\title{
A Mathematical Model of Organizing the Developmental Instruction in the System of Professional Education
}

\author{
Artem OBUKHOV, Denis DEDOV, Mikhail KRASNYANSKIY, Andrey POPOV
}

\begin{abstract}
One of the most important tasks of vocational education is to increase the intellectual potential of students, as this allows them to increase their competitiveness and demand for the labor market. The use of a competence-based methodological approach allows analyzing the processes taking place in the system of professional education and optimizing them. Within this study an original mathematical model of developing education was considered, which allows the decomposition, formalization and multi-criteria optimization of the learning process, and raise of its efficiency and effectiveness. Within the framework of the presented model, the key indicators of competency formation, the approaches to the organization of students' individual work are presented. An adaptive developmental education system was formulated and substantiated based on the conducted formalization of educational processes and the use of mathematical modeling methods, the methodology for designing. Successful solution to the problem of developing education optimization will provide the needs of the employer community for trained professionals, and students for high-quality, competitive education. The presented models and methods were used for the practical implementation of the information system of the score-rating system of a higher educational institution. The scientific results presented in the work can be used in the development and implementation of information systems for the management of vocational education, which will improve the quality of the educational process.
\end{abstract}

Keywords: adaptive control system for creative self-development; mathematical modelling; professional education, system analysis

\section{INTRODUCTION}

High-quality, creative, and innovation-ready specialists are becoming increasingly in demand at the modern labor market. The application of new approaches to the process of mastering the necessary level of competences is required to solve the problem of their preparation, modernization and optimization of the educational system. A lot of attention should be paid to the personalization of the educational trajectory of each student, the conscious mastering of the curriculum, the formation of competencies that are relevant and in demand at the labor market. The learner must develop a willingness to receive new knowledge, actively demonstrate their intellectual and creative abilities [1-4].

The specifics of organizing the educational process conditioned by traditional approaches (group work in lectures, practical and seminar sessions) and limited resources for students' independent work lead to insufficient effectiveness of classroom teaching, which currently dominates in professional education. Another issue is that study programs and classes tend to be targeted at average students, their level of abilities and motivation for learning. This approach ensures that all students develop knowledge and skills in the educational program in accordance with the FSES (Federal State Educational Standard) at the threshold level. However, such an approach creates certain difficulties in training of the technical "elite" for the needs of the regional economy and research organizations. Students who have a higher level of intelligence and an advanced initial level of preparation might lose interest in studying and switch to activities unrelated to the discipline once they have learnt new concepts and completed the assignments. This is largely determined by the insufficient level of intrinsic motivation of such students (and, first of all, by incomplete understanding of the relationship between studying and future career), as well as the low level of self-management. As a result, the most capable students, being ahead of their peers in academic work, will later create destructive facilitation and become a source of psychological discomfort for less capable or prepared students. The organization of the educational process, which does not take into account the capabilities of gifted students, leads to a decrease in the quality of their education and inhibition of the development of creative abilities that determine the success of innovative projects in their future professional work.

Working with small groups of students (from 10 to 15 people, in accordance with the calculation method of the ratio of number of students per teacher [5]), an experienced teacher who is aware of psychological characteristics of each student solves this problem by assigning an individual task to each student. To raise students' motivation for learning it is important to take into account their abilities and give assignments that slightly exceed their current level of competencies [6]. When working with large groups (from 15 students), it is more difficult for the teacher to implement this approach. A certain problem is that learning materials and tools are not differentiated by the degree of complexity; another challenge is insufficient individualized instruction and application of the principles of developmental learning in the system of professional training. Given the specifics of the faculty in higher educational institutions, this approach is mainly based on the intuitive views of the teacher on improving the effectiveness of educational activities. Besides, limited funding of universities and considerable workload of teachers hinders the effective implementation of this approach. To maximize the use of the entire study time and enhance the development of each student in accordance with their needs and abilities it is advisable to automate partially management of students' learning [7-10].

Modern information technologies offer new opportunities for differentiating the complexity of the curriculum for each student. A great role in this is played by the possibility of adapting the course of study to the students' abilities, their progress and the pace of learning. Dynamically generated tasks, tests, interactive teaching aids, as well as the use of virtual simulators are used to 
develop the necessary practical skills and to optimize the process of training. Information technologies make it much easier and more efficient to organize distance and extracurricular training. In accordance with the study schedule for each discipline (course) in the educational program a certain number of hours is allocated to independent work every academic week, and a certain amount of content of the academic discipline is planned to be studied by the average student. Such an approach to scheduling does not take into account students' abilities, their internal motivation and progress made in the previous modules of the discipline, as well as progress in other disciplines. In fact, these factors determine how much time a student can spend on independent study, what level of complexity of the new material and assignments can be given to students in the framework of developmental instruction.

In the context of the above studied features of professional training, it is possible to model the process of developmental instruction [7]:

- for self-study of assignments in the context of guided classroom work;

- for out-of-class independent work of students to develop competency components in the electronic educational environment.

The basic principle of these models will be the provision of each student with an assignment of increased complexity (in comparison with his level of knowledge and skills), taking into account his abilities, motivational readiness and limited resources, thus ensuring the implementation of the principle of developmental instruction. The implementation of this approach involves the development of a database of creative assignments in each discipline. The assignments must be targeted at the formation of competencies in accordance with the requirements of educational standards, as well as in terms of professional context, thus ensuring the formation of readiness to do the job in conformity with professional standards. At the same time, the information technologies and tools mentioned above will simplify the process of forming the database of assignments and varying their complexity [8].

Thus, within this study, it is necessary to solve the following tasks for the organization of developing education. Using data on individual characteristics of students and their progress, it is necessary to create a database of more complex assignments for classroom and independent work of students in order to increase the efficiency of the learning process. This will ensure both a high overall level of student development and will help accelerate the process of acquiring general and professional competencies, tailor the learning process to individual characteristics of each student, and raise motivation in gifted students.

The scientific novelty of the research consists in the development of an original mathematical model of the organization of developing education, allowing the decomposition, formalization and multi-criteria optimization of this process. The formulation of the optimization of the training process will take into account the factors of the complexity of the training course, the time of training, the compliance of the mastered competencies with the required discipline, material costs, etc. The obtained scientific results will allow formalizing, analyzing and improving the effectiveness of the process of developing education in the system of vocational education.

\section{LITERATURE REVIEW}

In order to solve the task of the organization of developing education, it is necessary to analyze the existing approaches to mathematical modeling and formalize the learning process in general, which will take into account the advantages and disadvantages of existing models and adapt them to the subject area, which will solve the problem.

In [11], the problem of developing training of engineers using modern information technologies was considered in detail. The approach, presented by the authors to the assessment of personal abilities, as well as systematized psychological metrics play an important role in the learning process modeling. Adapting this approach to the characteristics of developmental training, it is possible to compare the characteristics of the learner and the set of tasks in the training course, as well as to adjust the complexity of the tasks set to the person.

In the article [12], the mathematical model of education is considered from the point of view of the main stages of learning, the processes taking place in them and the set of rules used for the formation of educational material, the implementation of control actions and the educational process itself. This allows you to identify the main stages of the educational process, as well as use a certain set of production rules for the formation of individual tasks, their adjustment in the adaptation process to the individual characteristics of a person.

Another example of educational modeling is the context model presented in [13] and obtained on the basis of analyzing the knowledge sources and determining the dependence of the growth of the level of competencies on the source of knowledge. The approach, outlined in the article, assumes that person's competences are inseparable from his productivity in the workplace; therefore, diagnostics of workers and professional qualities can directly affect the process and content of training.

Modern theories, concepts, models and examples of learning using current technologies are presented in [2], [14-16]. The authors considered various options for structural and informational models of the educational process, researched the main components, but a rigorous mathematical model was not obtained.

Thus, the conducted analysis showed the need to develop a mathematical model for the organization of developing education, since the existing models do not fully formalize this process and do not allow it to be organized in an optimal way.

Next, we consider the question of a mathematical apparatus choice for the proposed model. The apparatus of the theory of sets is proposed as it allows one to formalize the main objects and their structure. Since the learning process can be considered from different sides, it will use a multi-criteria form of problem delivery when solving an optimization problem. This choice is justified by the complexity of the task and the possibility of the existence of a set of optimal solutions (Pareto-set), as well as 
successful experience in solving of multi-criteria optimization problems in this subject area [17-18]. The multi-criteria task is planned to be solved by highlighting one main criterion and putting all additional criteria into constraints.

After analyzing the existing approaches to the formalization of the learning process and the formulation of the problem of its optimization, we proceed to the development of a mathematical model of the organization of developing education.

\section{MATHEMATICAL MODEL OF DEVELOPING EDUCATION ORGANIZATION}

The conducted analysis of existing approaches to the formalization of the learning process allowed us to formulate the concept of the original mathematical model of the organization of developing education using the apparatus of the theory of sets.

This mathematical model will allow formalizing the process of teaching students both in classroom and outside. The initial information to construct the program of students' cognitive activity will include:

- general level of acquired competencies and the stage of studying the discipline in accordance with the curriculum;

- time and material resources available for students to complete assignments;

- components of professional and general competencies to be formed in this learning session (a fragment of the session).

In a formalized form, we will write the model of organizing the developmental instruction $M D E$ as follows:

$\operatorname{MDE}(S, R E S, D)=K_{0}$,

$K_{0} \subset K$,

where $S=\left\{s_{i}\right\}$ is a set of students characterized by the level of development of their abilities and the degree of mastering the curriculum.

$R E S=(T R, M R)$ is a set of resources available to students to complete assignments (time resources and material resources).

$D=\left\{d_{j}\right\}$ is a set of courses.

$K$ is a set of professional and general competencies, including a set of competences to be developed.

Each discipline has a set of assignments $Z_{j}$ and a set of competencies $K_{j}^{\mathrm{D}}$ developed in the study of the discipline:

$d_{j}=\left(Z_{j}, K_{j}^{\mathrm{D}}\right)$

Thus, in the process of organizing the developmental instruction, we must form the necessary set of competencies, taking into account available resources and the level of mastering disciplines and acquired competencies. Here arises the problem of assessing both the level itself and the educational tools necessary for the implementation of the learning process.

The priority of the formation of general competencies presupposes a greater emphasis on the forms and methods of work employed by the student. Formation of professional competencies predetermines a deeper relationship between the content of the assignment and the real situations typical of professional activities. This information allows selecting from the data-base the assignments that contribute (at different levels of development) to the achievement of the educational objectives of the lesson. Both closed (institutional) and open resources can be used as a database.

The complexity of the assignments in each discipline is determined by the following relation:

$z_{j m}=\left(c z_{j m}, d z_{j m}\right)$,

$z_{j m} \in Z_{j}$,

where $c z_{j m}, d z_{j m}$ is the content of the assignment and its relative complexity (for example, in the range from 0 to 100), respectively.

Individualization of learning and its developmental nature can be achieved by taking into account personal information about each student:

- level of intellectual and creative abilities required to complete the assignments;

- $\quad$ success of performing independent tasks in previous sessions (the time of implementation and the degree of achievement of the result).

Qualitative measurement of students' abilities is somewhat difficult, in part because of the laboriousness of psychological methods (for example, measurement of creativity) and the lack of professional psychologists in universities because of legal restrictions that prevent the use of such information in managing the learning process. It is noteworthy that the following psychological characteristics of an individual are of great importance: the level of introversion/extraversion, the personality type, the predominance of logic or imagination in the intellect, etc. [12]. It is difficult to get an accurate estimate of an individual on the basis of these metrics, but an expert evaluation makes it possible to select those forms of training that are most suitable for the individual in terms of their personality.

Currently, most higher education institutions are implementing in one form or another score-rating system (SRS) to assess students' progress, the indicators of which can be used to determine the students' abilities with a sufficient degree of accuracy. It should be noted that the question of using the SRS data for the management of the educational process requires a special study. It is necessary to distinguish clearly between the SRS activities, characterizing the degree of mastering the components of professional competencies, and activities whose main goal is a disciplining effect on the learner and assessment of the level of his self-management [13]. Teachers guided by the learning objectives of the course design the technology of using the SRS in a specific discipline. At the first stage of constructing a mathematical model of organizing the developmental instruction, we can use the SRS data in the form of the following components [14-19]:

- the absolute value of student's progress in the discipline to determine the possible excess of complexity of the assignments given to the student (compared to his level of knowledge and skills); 
- the relative proportion of the grades scored by a student in a particular discipline in the current semester to the maximum possible amount of points in the given period at the basic level of mastering competences, which basically characterizes the student's progress in the discipline;

- the relative proportion of the grades scored in all disciplines in the current semester to the maximum possible amount of points in the given period at the basic level of mastering competences, which basically characterizes the student's cognitive abilities and selfmanagement skills;

- the relative proportion of all previously scored grades to the average amount for the student group in order to determine the deviation of student's abilities from those of the average student (considering the distribution of students in the group according to ability as normal); the availability of data for independent monitoring of the competencies (results of Internet-based exams, testing in open education platforms, etc.) must be used to adjust this indicator.

Based on the above, one can form the main characteristics of the student in the model of organizing the developmental instruction:

$s_{i}=\left(P S_{i}, T R_{i}, P R S_{i}\right)$

where $P S_{i}$ is a set of psychological characteristics of the student obtained in the discipline of expert evaluation by a number of indicators (level of intelligence and creativity, moral and volitional qualities, style of thinking, communicative skills, etc.).

$T R_{i}$ is time available to the student both in class and out of class.

$P R S_{i}$ is a set of SRS points, characterizing the student's progress. We have already considered the main SRS components above, now we will present them in a formalized form:

$$
P R S_{i}=\left(A R_{i}, R R_{i}^{\mathrm{ALL}}, R R_{i}^{\mathrm{D}}, R R_{i}^{\mathrm{S}}\right)
$$

where $A R_{i}=\left\{a r_{i j k}\right\}$ is a set of absolute grades of $i^{\text {th }}$ student in $j^{\text {th }}$ discipline over $k^{\text {th }}$ period.

$R_{i}^{\mathrm{D}}=\left\{r r_{i j k}^{\mathrm{D}}\right\}$ is a set of relative grades of $i^{\text {th }}$ student in

$j^{\text {th }}$ discipline to the maximum possible in $k^{\text {th }}$ period.

$R R_{i k}^{\mathrm{ALL}}=\left\{r r_{i k}^{\mathrm{ALL}}\right\}$ is a set of relative grades of $i^{\text {th }}$ student in all disciplines to the maximum possible in $k^{\text {th }}$ period.

$R R_{i}^{\mathrm{S}}$ is a set of relative grades of $i^{\text {th }}$ student over the total period relative to the average statistical data for the group.

The formulas for the above evaluations are as follows:

- absolute grades in the discipline:

$a r_{i j k}=\sum_{m=1}^{M_{j}} O\left(s_{i}, z_{j m}\right)$

where $O\left(s_{i}, z_{j m}\right)$ is the student's score $s_{i}$ for the fulfillment (or non-fulfillment) of the assignment (activity in the SRS) $z_{j m} \in Z_{j}$;
- relative grades in the discipline for the selected period:

$r r_{i j k}^{\mathrm{D}}=\frac{a r_{i j k}}{d_{j k}^{\max }}$

where $d_{j k}^{\max }$ is maximum possible score in the $j^{\text {th }}$ discipline in $k^{\text {th }}$ period (basic level of mastering competencies);

- relative grades in all disciplines for the selected period:

$r r_{i k}^{\mathrm{ALL}}=\frac{\sum_{j=1}^{J} a r_{i j k}}{\sum_{j=1}^{J} d_{j k}^{\max }}$

- deviation from the average static score for the entire period of study:

$R R_{i}^{\mathrm{S}}=\frac{\sum_{j=1}^{J} \sum_{k=1}^{K} a r_{i j k}}{\overline{R R_{i}^{\mathrm{S}}}}$

$\overline{R R_{i}^{\mathrm{S}}}=\frac{\sum_{i=1}^{I} \sum_{j=1}^{J} \sum_{k=1}^{K} a r_{i j k}}{I}$

where $\overline{R R_{i}^{\mathrm{S}}}$ is the value of absolute grades of the average student.

Given the fact that in the organization of independent work not only the results of mastering the course modules, but also the pace of learning, and progress made in the previous practical assignments play an important role, it is necessary to take into account the previous independent work of students in the discipline. This information will be arranged in the form of a set of previously given assignments, with the data on the student's score and the time spent on completing the task, as well as the data on the ability of the student to make corrections after receiving instructions from the teacher or the information system, and the time spent on corrections. This brings us to the concept of assessing the development zone [12], which allows assessing the range of problems that a student is able to solve on his current level of abilities. The assignments of increased complexity located outside this zone make it possible to activate thinking skills and maintain the student's interest in the discipline. To determine the zone of proximal development, we use the following relation:

$v d_{i j}=E F\left(\mathrm{SRS}_{i}, S P_{i j}\right)$,

$S P_{i j}=\left\{\left(z_{j m}, t_{j m}, c d_{j m}\right)\right\}$

where $v d_{i j}$ is the development zone within the discipline $d_{j}$.

$E F$ is the function that assigns a certain value in a given range (for example, from 0 to 100) corresponding to the student's scores in the SRS and information about previously solved problems, corresponding to the student's development zone $s_{i}$. 
$S P_{i j}$ is a set of data on the assignments completed by the student, including the assignments themselves $z_{j m}$, the time spent on completion $t_{j m}$ and evaluation of the correctness of the solution $c d_{j m}$.

Thus, assignment $z_{j m}$ with the given complexity $d z_{j m}$ can be solved by student $s_{i}$ with the development zone $v d_{j m}$ equal to or exceeding the complexity of the assignment.

The presented mathematical model of the organization of developing education allows you to formalize the characteristics of students and their performance in SRS. Its distinctive feature is the formalization of the main components of the educational process, the ability to assess student performance on various indicators, as well as taking into account the varying degrees of complexity of the tasks of the training course, which allows it to be adapted to the individual characteristics of each student.

Using this information, one can formulate the problem of finding the optimal set of assignments for classroom and extra-curricular work.

\section{FORMULATION OF THE PROBLEM OF ORGANIZING DEVELOPMENTAL INSTRUCTION}

We start with the formulation of the problem of organizing the developmental instruction for independent completion of assignments in the classroom. The need for such teaching method in professional training is explained by the fact that, when studying in a group students might not be fully aware of the logic and features of a particular component of the professional activity. This problem can be solved only by involving each learner in the activity, which, in turn, presupposes both individualization of training and assignments.

In a formalized form, the problem looks like this: it is necessary to find the extremum of the objective function of the average complexity assignments, which depends on the disciplines in the curriculum and the set of assignments $Z_{j}^{\text {opt }}$ for each student $s_{i}$ :

$$
R(D)=\frac{\sum_{i=1}^{I} \sum_{j=1}^{J} \sum_{m=1}^{M_{j}} d z_{j m}^{\mathrm{opt}}}{I \cdot J} \rightarrow \max
$$

if the constraint equations in the form of a mathematical model of the organizing the developmental instruction:

$$
\begin{aligned}
& s_{i} \rightarrow\left\{Z_{j}^{\mathrm{opt}}\right\}, \\
& Z_{j}^{\mathrm{opt}} \rightarrow\left\{d z_{j m}^{\mathrm{opt}}\right\}, \\
& v d_{i j} \rightarrow \Delta d e_{i j}, \\
& Z_{j}^{\mathrm{opt}}=\left\{z_{j}^{o p t} \mid d z_{j}^{o p t}-v d_{i j} \leq \Delta d e_{i j}\right\} .
\end{aligned}
$$

and restrictions on the following are satisfied:

- the study time:

$$
\sum_{i=1}^{I} \sum_{j=1}^{J} t_{j m} \leq t_{0}
$$

- compliance of mastered competencies for the $K_{j}^{\mathrm{D}}$ disciplines with the set of required competencies $K_{0}$ :

$$
K_{j}^{\mathrm{D}} \subset K_{0}
$$

- $\quad$ the required time resources $T R_{i}$ of student $s_{i}$ :

$T R_{i} \leq T R_{0}\left(s_{i}\right)$

- the required material resources $M R$ of the educational institution:

$M R \leq M R_{0}$

where $R(D)$ is the optimization criterion characterizing the average complexity of the assignments completed in the disciplines $D$.

$\Delta d e_{i j}$ is the degree of adding complexity in the discipline $d_{j}$, corresponding to the development zone of each student $s_{i}$ and determining in what range it is possible to increase the complexity of new assignments. If we assume $\Delta d e_{i j}=0$, then all assignments will fall into the student development zone.

$t_{0}$ is the total pre-set time allocated for completion of the assignments.

$T R_{0}\left(s_{i}\right)$ is maximum time available to student $s_{i}$

$M R_{0}$ is maximum material resources for the learning process.

Next, we consider the formulation of the problem of organizing the developmental instruction in out-of-class independent work, in the modeling of which both the set of input information flows and their semantic content change. Primarily, it concerns the time spent by the student on independent work in this period of study. Firstly, designing student's individual educational trajectory depends on the intrinsic motivation for cognitive activities, the desire to develop a certain competency or learn how to fulfill a certain labor function demanded by a potential employer and availability of free time. Secondly, unlike independent work in the classroom, this type of activity involves the development of skills and acquisition of new knowledge, which a student can get from the information sources recommended by the teacher, as well as from the sources found by the student through independent search. Thirdly, it is necessary to take into account students' progress in other academic disciplines (in the form of the relative proportion of grades in each discipline in the current semester to the maximum possible grades in the given period at a basic level of mastered competencies, and the relative proportion of grades a student can get in the short term to the maximum possible grades in each discipline). In such a case, it will determine the redistribution of independent work time in the direction of the disciplines, which require additional training and are essential for the final ranking of students. It should be noted that this redistribution of time has the character of operational management and allows students to reach the planned level of mastering competencies in accordance with the study program with minimum losses and to eliminate shortcomings of pedagogical activity of some teachers. 
Given the above features, we formulate the problem of organizing the developmental instruction for out-of-class independent work as follows: it is necessary to find the extremum of the objective function $R$ of the average complexity of the assignments for the selected disciplines of the curriculum, according to which the student has the lowest academic performance:

$R\left(D^{*}\right)=\frac{\sum_{i=1}^{I} \sum_{j=1}^{J} \sum_{m=1}^{M_{j}} d z_{j m}^{\mathrm{opt}}}{I \cdot J} \rightarrow \max$

If the constraint equations in the form of a mathematical model of organizing the developmental instruction:

$$
\begin{aligned}
& s_{i} \rightarrow\left\{Z_{j}^{\mathrm{opt}}\right\}, Z_{j}^{\mathrm{opt}} \rightarrow\left\{d z_{j m}^{\mathrm{opt}}\right\}, v d_{i j} \rightarrow \Delta d e_{i j}, \\
& Z_{j}^{\mathrm{opt}}=\left\{z_{j}^{\mathrm{opt}} \mid d z_{j}^{\mathrm{opt}}-v d_{i j} \leq \Delta d e_{i j}\right\}
\end{aligned}
$$

and restrictions on the following are satisfied:

- a set of disciplines, in which the student $s_{i}$ has the lowest academic performance:

$s_{i} \rightarrow D^{*}=\left\{d_{j} \mid r r_{i j k}^{\mathrm{D}} \rightarrow \min \left(R R_{i}^{\mathrm{D}}\right)\right\}$

- compliance of mastered competencies $K_{j}^{\mathrm{D}}$ for the disciplines with the set of required competencies $K_{0}$ :

$K_{j}^{\mathrm{D}} \subset K_{0}$
- $\quad$ the required time resources $T R_{i}$ of student $s_{i}$ :

$T R_{i} \leq T R_{0}\left(s_{i}\right)$

- the required material resources $M R$ of the educational institution:

$M R \leq M R_{0}$

where $R\left(D^{*}\right)$ is the optimization criterion characterizing the average complexity of the assignments completed in the selected disciplines $D^{*}$.

$s_{i} \rightarrow D^{*}$ is the relation that determines the correspondence between students and those disciplines, where their relative grades $r r_{i j k}^{\mathrm{D}}$ tend to minimal.

Thus, the key difference between the out-of-class work of students from that in the class-room is in the absence of time constraints on completion of assignments, as well as the choice of complicated tasks for those disciplines, in which students have insufficient academic performance.

\section{PRACTICAL APPLICATION OF DEVELOPED MATHEMATICAL MODEL}

The developed within this study mathematical model of developing education has been successfully implemented in the form of SRS software of TSTU applied to assess the progress of university students. The fragment of this software is presented in Fig. 1.

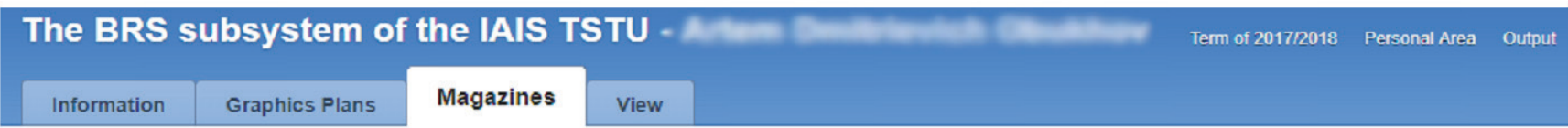

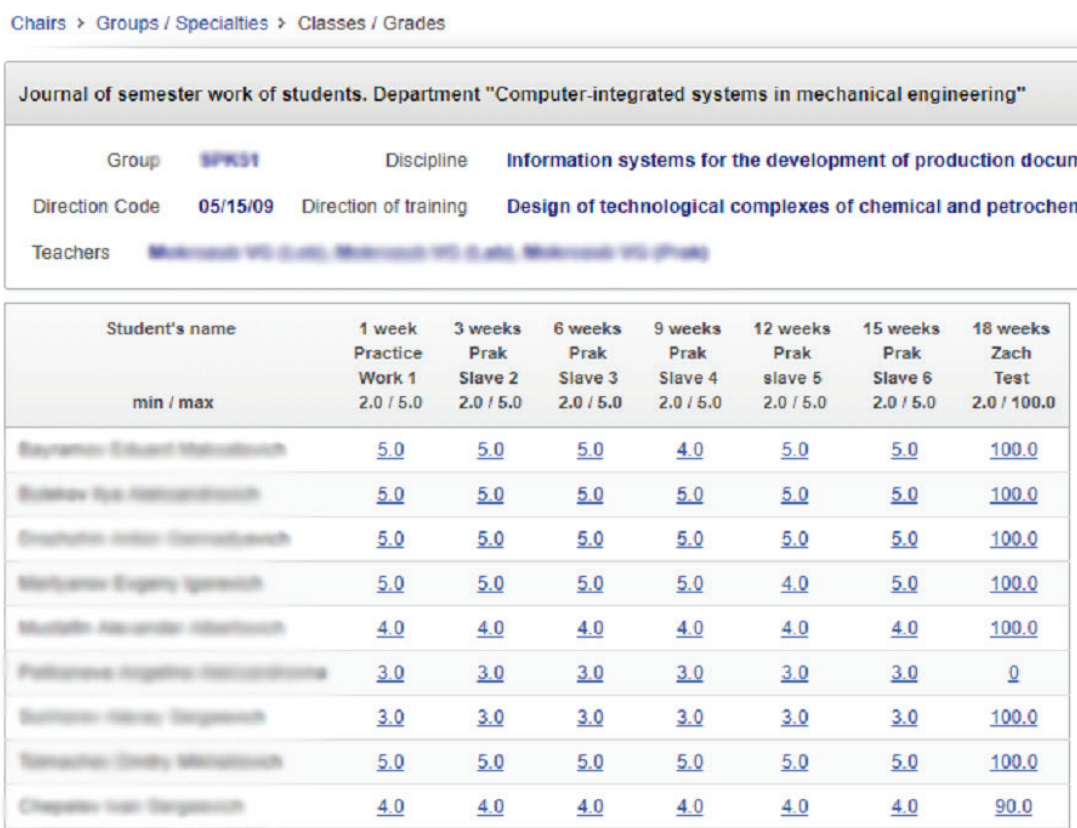

Figure 1 Fragment of SRS software 
In order to implement the adaptive control of selfeducation using the developed mathematical model, instrumental and pedagogical tools in the form of creative tasks of varying complexity, constructed to form universal and professional competencies, were designed [26-27].

The practical application of the presented mathematical model is not limited to the realization of developmental instruction at universities and higher educational institutions; this concept can be used to train employees of various industrial enterprises in order to improve their qualifications. Classical training based on a set of assignments with the minimum level of complexity, of course, allows employees to develop a basic level of professional competencies, but in real life skilled workers are expected to do the job not only within the limits of the regulations, but also beyond them. An example of such activities is counteraction to emergencies, which require special training. The use of developmental instruction makes it possible to build a training program in such a way that the ever-increasing complexity of assignments will eventually lead to transition from exercises used in the regular mode to those applied to emergency conditions. Obviously, this is impossible without using modern information technologies, visualization and training systems, however, it is the concept of developmental learning that makes it possible to organize the training process effectively, to determine the sequence of assignments and their complexity, to assess the trainee's progress and level of development.

The presented mathematical model is notable for its versatility; by the concept of assignment, we mean a wide range of different forms of learning activities, including tests, solving theoretical and practical problems, as well as advanced teaching methods, such as training on virtual simulators, interactive learning tools, and customized learning systems. Similarly, instead of the concept of SRS, it is possible to use any other scale for assessing student's progress, as the model does not impose any restrictions on it, allowing for full implementation of the methodology for assessing trainees' abilities, which is necessary for the correct calculation of learners' development zone.

This confirms the universality of the proposed mathematical model, its applicability not only for the organization of developmental instruction for university students, but also for training of industrial workers, including training on simulators.

The optimization of developing education organization in the vocational education system based on the developed mathematical model will allow the educational institution to:

- increase the satisfaction of consumers of educational services by expanding the number and focus of educational programs that take into account both the actual needs of employers and the educational needs of the student himself,

- implement advanced training programs taking into account the prognosis of the needs of the regional labour market,

- increase the number of total number of university students at the expense of students according to individual curricula, which will reduce the cost of a number of educational services,
- optimally use the creative, scientific and methodological potentials of the scientific and pedagogical staff of the university in the creation of instrumental and educational tools that ensure the implementation of innovative educational technologies, including in the digital educational space,

- increase the proportion of the development time of the educational program, aimed at educational and professional creativity, and, accordingly, at preparing for innovative activities,

- optimize the use of research laboratories of the university in the formation of the skills and abilities of research activities, to actively implement the scientific achievements of university employees in the educational process.

\section{DISCUSSION}

The effectiveness improvement of vocational education, the formation of creative qualities and universal competencies of a specialist, allowing a university graduate to quickly and painlessly join the activities of enterprises and organizations on innovative renewal of production is one of the most important tasks for society. The need to keep the traditions of quality for Russian education with continuous updating, using the achievements of pedagogical innovation and the active digitalization of all spheres of the economy, complicated by insufficient quality of regulatory and legal support, actualizes the development of new approaches to education control. At the same time, the maximum emphasis should be placed on individualizing education, taking into account personal characteristics and the current dynamics of the student's development, as well as developing his creativity and readiness for independent creative self-development.

The elements of developing education have been used in the system of vocational education. The problem issue is the transition from private educational practices of using developing education (based largely on the personality of a particular teacher, his charisma and readiness for pedagogical creativity) to a systematic construction of the creative educational process, its monitoring and management based on an analysis of the objective and subjective characteristics of the learning process.

The concept of an original mathematical model of the organization of developing education using the set theory apparatus was proposed to solve this problem. This mathematical model will allow you to formalize the process of teaching students both during contact work and, most importantly, at independent learning of the material and the formation of the necessary professional skills. When developing a mathematical model, the main components of the learning process were formalized (a list of planned learning outcomes, used material and technical resources, and instrumental and pedagogical tools). In order to manage the process of education and selfeducation, a methodology is proposed for assessing student performance using various indicators, which make it possible to identify both methodological difficulties in mastering the program and the influence of personality traits and students on achieving a planned result. A methodology for designing assignments of varying degrees of complexity was developed, allowing solving various 
educational tasks in accordance with the motivational readiness and professional self-determination of each student. The monitoring mechanism of the student's educational activities, taken into account in the developed model, and the ability to design instrumental and pedagogical tools of various levels of complexity and practical orientation make it possible to organize adaptive management of vocational education.

The developed model will be used to optimize the organization of developmental education in order to maximize the student's educational needs (forming a set of professional competencies demanded by employers by changing the parameters of the educational process - the content of training, forms and methods of organizing the educational process, applied pedagogical tools) with optimal use of both its time and personal characteristics and used resource of university: material and technical base, capacity and time of academic staff.

A system for monitoring the current level of competence formation in the format of a point-rating system, implemented at the university, was used for adaptive control of a developmental training.

The representation of a mathematical model for the organization of developing education will make it possible to develop a more effective solution of the scientific problem of training of technical specialists for innovation activity, which has a major socio-economic importance in the context of ensuring economic security and innovative development of the country.

\section{CONCLUSION}

Thus, we considered modelling of organizing the developmental instruction both in the classroom and for out-of-class independent work. The ability to select assignments of increased complexity, given the current level of students' development and their intrinsic motivation, makes it possible to use the model of developmental learning to manage training of high-profile professionals through independent work.

The scientific results presented in the article can be used to model the educational process of various types, since the proposed mathematical model takes into account the varying degree of complexity of assignments, and allows building a model of the basic level of education simplified for students with limited abilities, etc.

The authors' contribution to the research in this subject area consists in analyzing the process of developing education, design of a methodology for assessing students' achievements in accordance with a score-rating system, and formalizing the tasks of optimizing the process of developing education in classroom and extracurricular work. The scientific novelty of the research consists in the development of an original mathematical model of the organization of developing education, which allows the decomposition, formalization and multi-criteria optimization of the training process, the increase of its efficiency and effectiveness.

Universal approaches to formalization of organizing the process of training, to determining the complexity of assignments and improving the learners' abilities through the transition from the development zone to the immediate development zone and further development zone are of significant theoretical and practical importance when improving the organization of the learning process.

\section{Acknowledgements}

The work was supported by the Russian Ministry of Education as part of the project part (project 8.2906.2017/PP).

\section{REFERENCES}

[1] Popov, A. I. \& Polyakov, D.V. (2016). Metodicheskie voprosy razrabotki adaptivnoj informaci-onnoj sistemy soprovozhdenija tvorcheskoj raboty obuchajushhihsja [Methodological issues of developing customized information systems to support the creative work of students]. Jeko-potencial (Eco-potential), 3(15), 18-28.

[2] Ivanov, V. G., et al. (2014). Regional experience of students' innovative and entrepreneurial competence forming. Review of European Studies, 7(1), 35-40. https://doi.org/10.5539/res.v7n1p35

[3] Torkunova, J. V., et al. (2014). The peculiarities of qualitative information, analytical maintenance innovative and educational activity technological projection in higher educational institution. Life Science Journal, 11(8), 498-503.

[4] Simonova, G. \& Sadovaya, V. (2016). Socio-pedagogical complex as a pedagogical support technology of students' social adaptation. International Journal of Environmental and Science Education, 11(8), 2069-2083.

[5] Mihalkina, E. V., Skachkova, L. S., \& Gaponenko, N. V. (2013). Analiz norm truda professorsko-prepodavatel'skogo sostava vuza (Analysis of labor standards of the faculty of the University). Ehkonomika obrazovaniya, 2, 21-33.

[6] Popov, A. I., (2013). Prepodavatel' vuza kak organizator tvorcheskogo samorazvitija studenta (A university lecturer as the organizer of creative self-development of students). Alma-mater: Vestnik vysshej shkoly, 9, 48-51.

[7] Merzon, E. E., et al. (2014). Organizational and pedagogical conditions of academic mobility development of students at school of higher professional education. Review of European Studies, 7(1), 46-51. https://doi.org/10.5539/res.v7n1p46

[8] Khusainova, R. M., Chirkina, S. E., \& Gabdrakhmanova, R. G. (2015). The Role of the Reflective Activity of Students in Individual Educational Trajectory. Review of European studies, 7(5), 146-152. https://doi.org/10.5539/res.v7n5p146

[9] Krasnjanskij, M. N. et al. (2015). Proektirovanie informacionnyh sistem upravlenija doku-mentooborotom nauchno-obrazovatel'nyh uchrezhdenij: monografija (Designing of electronic document management systems for research and educational institutions: monograph). Tambov: Izd-vo FGBOU VPO "TGTU", 216.

[10] Kurilovas, E., Kubilinskiene, S., \& Dagiene, V. (2014). Web 3.0-Based personalisation of learning objects in virtual learning environments. Computers in Human Behavior, 30, 654-662. https://doi.org/10.1016/j.chb.2013.07.039

[11] Diakonov, G. S. et al. (2009). Podgotovka inzhenera v real'no-virtual'noj srede operezhajushhego obuchenija (Training of engineers in the advanced real-virtual environment). Kazan': KGTU, 395.

[12] Ryzhkova, M. N. (2015). Matematicheskaya model' processa upravleniya obucheniem (Mathematical model of the learning management process). Vestnik Cherepoveckogo gosudarstvennogo universiteta, 6(67).

[13] Ley, T. et al. (2008). Modeling competencies for supporting work-integrated learning in knowledge work. Journal of Knowledge Management, 12(6), 31-47. https://doi.org/10.1108/13673270810913603

[14] Hung, D. \& Khine, M. S. (ed.). (2006). Engaged learning with emerging technologies. Springer. 
https://doi.org/10.1007/1-4020-3669-8

[15] Rahamat, R., et al. (2011). Learners' Evaluation of an eLearning Material. Proceedings of the $10^{\text {th }}$ WSEAS eActivities.

[16] Berestneva, O., et al. 2015). Students' Competence Assessment Methods. Procedia-Social and Behavioral Sciences, 166, 296-302. https://doi.org/10.1016/j.sbspro.2014.12.527

[17] Mukhametzyanov, I. \& Pamucar, D. A. (2018). Sensitivity analysis in MCDM problems: A statistical approach. Decis. Mak. Appl. Manag. Eng., 1, 51-80. https://doi.org/10.31181/dmame1802050m

[18] Popovic, M., Kuzmanović, M., \& Savić G. (2018). A comparative empirical study of Analytic Hierarchy Process and Conjoint analysis: Literature review. Decision Making: Applications in Management and Engineering, 1(2), 153163. https://doi.org/10.31181/dmame1802160p

[19] Mittal, S. \& Dhar, R. L. (2015). Transformational leadership and employee creativity: mediating role of creative selfefficacy and moderating role of knowledge sharing. Management Decision, 53(5), 894-910. https://doi.org/10.1108/MD-07-2014-0464

[20] Csikszentmihalyi, M. \& Wolfe, R. (2014). New conceptions and research approaches to creative-ty: Implications of a systems perspective for creativity in education. The systems model of creativity. - Springer Netherlands, 161-184. https://doi.org/10.1007/978-94-017-9085-7_10

[21] Hodara, M. \& Jaggars, S. S. (2014). An examination of the impact of accelerating community college students' progression through developmental education. The Journal of Higher Education, 85(2), 246-276. https://doi.org/10.1080/00221546.2014.11777326

[22] Clotfelter, C. T., et al. (2015). Developmental education in North Carolina community colleges. Educational Evaluation and Policy Analysis, 37(3), 354-375. https://doi.org/10.3102/0162373714547267

[23] Crisp, G. \& Delgado, C. (2014). The impact of developmental education on community college persistence and vertical transfer. Community College Review, 42(2), 99117. https://doi.org/10.1177/0091552113516488

[24] Burger, K. (2010). How does early childhood care and education affect cognitive development? An international review of the effects of early interventions for children from different social backgrounds. Early childhood research quarterly, 25(2), 140-165. https://doi.org/10.1016/j.ecresq.2009.11.001

[25] Hodara, M. \& Xu, D. (2016). Does developmental education improve labor market outcomes? Evidence from two state. American Educational Research Journal, 53(3), 781-813. https://doi.org/10.3102/0002831216647790

[26] Popov, A. I. (2010). Teoreticheskaya mekhanika. Sbornik zadach dlya tvorcheskogo samorazvitiya lichnosti studenta: uchebnoe posobie [Theoretical mechanics. Collection of tasks for creative self-development of the student: textbook]. Izd-vo GOU VPO TGTU, 188.

[27] Puchkov, N. P. (2012, 2013). Primenenie matematicheskih znanij $v$ professional'noj deyatel'nosti. Posobie dlya samorazvitiya bakalavra. V 4-h chastyah (Application of mathematical knowledge in professional activities. Guide to self-development bachelor's degree. In 4 parts). N. P. Puchkov, T. V. ZHukovskaya, E. A. Molokanova, I. A. Parfenova, A.I. Popov. - Tambov: Izd-vo FGBOU VPO "TGTU", 320.

\section{Contact information:}

Artem OBUKHOV, PhD

(Corresponding author)

Tambov State Technical University,

392000, 106, Sovetskaya Str., Tambov, Russia

E-mail: obuhov.art@gmail.com

\section{Denis DEDOV, PhD}

Tambov State Technical University,

392000, 106, Sovetskaya Str., Tambov, Russia

E-mail: hammer68@yandex.ru

\section{Mikhail KRASNYANSKIY, Prof.}

Tambov State Technical University,

392000, 106, Sovetskaya Str., Tambov, Russia

E-mail: kras@tambov.ru

\section{Andrey POPOV, PhD}

Tambov State Technical University,

392000, 106, Sovetskaya Str., Tambov, Russia

E-mail: olimp_popov@mail.ru 